\title{
One Century of Pre-Emptive and Preventive Analgesia. A Tribute to George Washington Crile
}

\author{
Volume I Issue 5 - 2014
}

\section{Opinion}

A hundred years ago, George Washington Crile MD (Figure 1), an Ohio born surgeon published his book on Anoci-Association ${ }^{1}$ based on his clinical observations using presurgical injection of morphine, pre and transoperative local anaesthetics infiltration of the surgical field. One year before, Crile published in Lancet an article entitled The kinetic theory of shock and its prevention through Anoci-association (Shockless operation). ${ }^{2}$ In both documents he describes his ideas on how to prevent surgical pain, to enhance patient safety during surgery, and to improve postsurgical outcome of his patients. Besides other investigations, his particular interest on surgical pain was the original idea that several decades later lead some researchers to determine the role of local anaesthetics and analgesics administered before surgery to what now is known as pre-emptive and preventive analgesia.

Born in November 11, 1864 in a small farm near Chili Ohio, Dr. Crile was the fifth of eight children of a Dutch and Scottish-Irish family. He grew up in his born town, under a close supervisioneducation of his parents, who taught him to read, count and show interest in nature. After he finished elemental school in a one-room teaching-house two miles from his farm, George W. Crile entered Northwestern Ohio Normal School and become a teacher at the age of 18 . He worked in elementary schools and soon was the Principal of the Plainfield School in Ohio.

Although his mother had some rural medical knowledge, his interest in medicine derived from his friend Dr. A.E. Walker, the village physician, who loaned some of his books, give him the privilege of reading in his library, and also invited Crile to see some of his patients. In 1886, when he was 21 years old, entered Wooster Medical School in Cleveland, Western Reserve University, an inexpensive school that only met in summer sessions. He was able to support his medicine school fees working at Plainfield School until he graduated with the highest honors in July 1887, at the age of 22, after only eight months of attending medical school. Immediately after his medical graduation, Crile entered University Hospital in Cleveland as intern under the tutelage of Dr. Frank C. Weed (Figure 1).

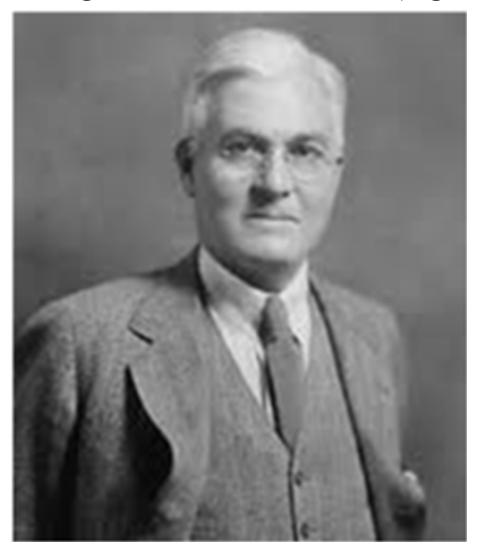

Figure I George Washington Crile. 1864-1943.

\author{
Victor MWhizar-Lugo \\ Department of Anesthesiology, Centro Médico del Noroeste, \\ México
}

Correspondence: Victor MWhizar-Lugo, Internal Medicine, Intensive Care,Anesthesiology, Centro Médico del Noroeste, Misión de San Diego 2993-306, Zona Urbana Rio Tijuana,Tijuana BC, México CP 22320, México, Tel +52-664-684-8905, Fax +52664-684-8906,Email vwhizar@anestesia-dolor.org

Received: November 14, 2014 | Published: November 22, 2014

Crile was interested in studying shock when he was a house officer in Dr. Weed's service and saw for the first time the death of a person; a young man involved in an accident and died in shock soon after his lower extremities were amputated by Dr. Weed. In his autobiography he wrote: "I sat beside the bed of this vigorous young friend of mine, studying his failing body energies. During my vigil throughout the night, I, a new intern without experience and never having seen a serious illness, read the various surgical opinions regarding this type of injury and the treatment recommended, making notes in my diary on the changing condition of the patient. "Crile ${ }^{3}$ performed the autopsy on his friend-patient and the findings were compared with the data found in a cat which he induced traumatic shock with the idea to understand what had happened to his dead patient.

After his internship, he joined his mentor Weed, and Dr. Frank E. Bunts, to work in private practice. They created a large and successful surgical practice. Crile continued interested in shock and spent three months at the College of Physicians and Surgeons of Columbia University studying histology, physiology and pathology in order to deeply comprehend traumatic and surgical shock. He went to London and met Charles Scott Sherrington, a physiologist also interested in shock and hypertension. When Crile returns to Cleveland, he continued his studies on shock. He thought that shock was due to the exhaustion of the vasomotor center. His research in shock allowed him to won in 1897 the Cartwright Prize awarded by Columbia University. His paper entitled Experimental research into surgical shock was published by J.B. Lippincott in 1899. This was his first book.

Among other surgical fields, George W. Crile was passionate about thyroid surgery. He performed over 25,000 thyroidectomies in his career, and became the top expert American surgeon in the field. ${ }^{4,5}$ In his autobiography he described two patients who marked his practice; the first patient was a young medical student, son of a general practitioner, who had uncontrollable hyperthyroid exophthalmic goiter. Patient and father insisted in surgery. Under ether anaesthesia, Crile carefully removed his thyroid gland, but the patient died few hours after surgery due to a severe hyperthyroid crises. A few days later, a young lady with hyperthyroid exophthalmic goiter went to consult with Dr. Crile. 
Although he took her to the surgical room, he returned the patient to her room without even try anaesthesia. She also died soon after few days due to a thyroid storm. He thought that fear was a major factor in these two patients with Graves' disease and decided to eliminate this fear in his next cases before taking them to surgery. His next patient with hyperthyroid goiter was sedated with morphine and ether in her hospital room, isolated from the environmental darkening the room, corneal homatropine to blurred her vision, and lessen hearing with moist cotton into her ears. Once the patient was asleep, she was taken to the operating room and under ether anaesthesia her thyroid gland was successfully removed by Crile. Later, he decided to infiltrate local cocaine before starting the surgery, with the idea of blocking nociceptive stimuli from the operative trauma. According to his autobiography, ${ }^{3}$ hyperthyroid patients were the most benefited from his complete surgical anaesthesia procedure.

His idea of complete operative anaesthesia, which he named Anociassociation ${ }^{1-3}$ was to block all the possible noxious stimulus caused not only by surgery, but also those stimulus from the aggressive hospital environment and the disease itself. Dr. Crile new coined word, which literally means absence of damaging associations, was influenced by the knowledge of his European mentor Sherrington. ${ }^{1,3}$ The first coined term was Noci-Association, then Anoci-Association, subsequently contracted to Anociation. Many years later Woolf, ${ }^{6,7}$ Wall, ${ }^{8}$ Dickenson et al. ${ }^{9}$ demonstrated that administration of opioids or local anesthetics before noxious stimulus can prevent the development of injuredspinal hyperexcitability and pain related behavior. ${ }^{10}$ The first clinical paper on pre-emptive analgesia was published by Tverskoy et al., ${ }^{11}$ Figure 2 shows a diagram of the current concept of pre-emptive and preventive analgesia.

\begin{tabular}{|r|l|l|}
\hline Pre-emptive & \\
\hline $\begin{array}{c}\text { Before surgical } \\
\text { incision }\end{array}$ & During Surgery & After Surgery \\
\hline P r e v e n t i v e \\
\hline
\end{tabular}

Figure 2 Pre-emptive analgesia is achieved with analgesics, local anaesthetics and adjuvants drugs administered before surgery begins. Preventive analgesia refers to drugs given before, during and after surgery.

As mentioned before, the theory of anociation came out from his investigations on shock and exhaustion. Crile supposed that intense fear and harmful stimulus lead to development of shock; both emotional and physical stimuli acting on the central nervous system were capable to cause shock during the surgical procedures, and this final event could be prevented by blocking every stimulus from reaching the brain. In his famous diagram (Figure 2), Crile shows three individuals; the first one is a conscious patient in which stimulus from his sense organs and a harmful stimulation applied with a needle in his leg (peripheral nociceptors) are transmitted to the brain producing exhaustion and shock. The next individual is under the effect of general anaesthesia; this patient do not perceive stimulus from his sense organs, but the noxious somatic stimulus from the traumatic needle inserted in his leg are able to reach his brain. The third and last patient summarizes anoci-association theory; is also a patient under general anaesthesia, but has a peripheral nerve infiltrated with cocaine blocking the transmission of painful stimulation. According to Crile, the brain of this person is totally protected against all external stimulation (Figure 3). ${ }^{1,2,12,13}$
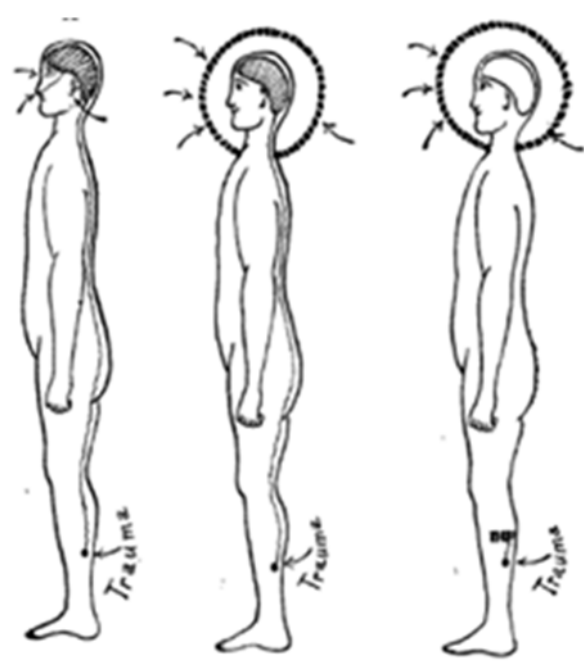

Figure 3 Crile's original diagram to explain the anoci-association. Two concepts are basic; prevent nociceptive and non-nociceptive impulses reach the brain, and the peripheral blockade of harmful stimulus with local anaesthetics.

At the age of 57, George W. Crile was one of the four founders of the Cleveland Clinic; together with William E. Lower, Frank E. Bunts and John Phillips opened the hospital in February 26, 1921 with goals to provide patient care, research, and medical education. He was president of the Cleveland Clinic from 1921 to 1940 and as trustee from 1921 to 1936. Interesting, on pages 383-4 of his autobiography he wrote: "Yet there is no possibility of financial benefit accruing to the Founders from any research. I never cease to feel pride in the medical profession that from the earliest times a rigid code has prevented the patenting for personal profit or the keeping secret of any knowledge or instrument or method or idea that the profession has developed for the good of mankind. Every discovery is published and is as readily available to every other physician as to the discoverer himself -the theory being that medical facts have a direct bearing upon life and death, therefore in the public interest such contribution cannot be for sale". ${ }^{3}$ These concepts may be taken as the basis of the actual concept of open access and free access that many current medical and non-medical journals and books use for all or part of their articles that are available for free on the WEB. In fact, the prestigious Cleveland Clinic Journal of Medicine is a publication which can be accessed freely in articles since 1939. Crile not only had the idea that biomedical information should be free, also founded scholarships for young doctors who were visitors at the Cleveland Clinic, and made significant financial support for research.

In addition to his theories on surgical shock and the prevention and management of surgical pain, he became interested in monitoring blood pressure during surgery by promoting the use of the Riva Rocci sphygmomanometer, demonstrated the importance of measuring central venous and peripheral pressure, used bicarbonate salts and epinephrine, did numerous studies on resuscitation, and realized that the intravenous saline solutions were useful for a short period of time so hemotransfusions used more efficiently. Indeed, in August 1906 he performed the first successful blood transfusion in humans in United States of America. Invented the anti-shock garment, a pneumatic rubber suit designed to reduce postural hypotension in neurosurgical cases, and used later during the II World War in pilots. This garment was used during the Vietnam War to stabilize patients with hemorrhagic shock. ${ }^{13-15} \mathrm{He}$ was a master in cancer neck surgery and is credited with the first laryngectomy in America. Crile also 
studied comparative anatomy of the endocrine system. He invented the mosquito hemostats, which bear his name. He acted as military surgeon in Cuba and Puerto Rico during the Spanish-American war In World War I he was director of surgery at the American Ambulance Hospital in Neuilly France. In 1913 he co-found the American College of Surgeons, and was also a member of the American College of Surgeons, American Medical Association, American Surgical Association, Royal Academy of Surgeons and the Royal Academy of Medicine.

In 1936, The Chief, a well-known nickname for Dr. Crile, was diagnosed with bilateral cataracts. His sight was gradually affected and had to change his lifestyle: learn to give his lectures without notes, memorized long list of fellowships, and even perform some surgeries primarily using tact. He developed his sense of touch and was able to perform celiac ganglionectomies, pelvic surgery and even thyroid operations. In his autobiography he wrote: “.....the seeing eye of my fingers, to convert an apparently impossible technique into an every-day operation". In 1940 he had cataracts surgery, but his right eye became infected and had to be enucleated by his friend Dr. Ruedemann. After a quick recovery, Crile continued his research on erythrocytes, brain, adrenal and thyroid glands. Crile and his wife Grace survived a plane accident while returning home from one of his study trips; broken ribs, pelvis and spine kept him in a small hospital in Vero Beach, far from Cleveland. At the age of 76, Crile was appointed by the Navy Secretary as Honorary Consultant of the Medical Department, receiving one dollar a year.

In 1942 he wrote an speech paper to be presented at the 25th Anniversary of Lakeside Unit II, Lakeside Hospital, but he was unable to delivery his presentation because severe fever that required hospitalization at the Cleveland Clinic on November 10, just one day before his 78th birthday. He was diagnosed with $S$. faecalis endocarditis and was treated unsuccessfully with sulfas and penicillin. On January first, 1943 the Chief developed hemiplegia and dye on January 7 th. He was 78 years old.

George Washington Crile was a surgeon of international reputation forged in an era when surgery was rude and anaesthesiology was an act of resistance to pain. He was born as a researcher and known as the Father of Physiologic Surgery. ${ }^{16}$ Unfortunately many of his concepts were forgotten after his death, although some of them were rescued decades later, such is the case of pre-emptive and preventive analgesia. How much Crile's idea influenced subsequent research on the perioperative use of local anesthetics, analgesics, and adjuvant drugs is merely unknown. However, Crile publications are mentioned in most of the initial studies on this subject, and of course, in all the papers on the interesting life of this surgeon. He published more than 400 papers and 24 books; his scientific legacy is huge when compared to the time in which he lived. He was a close observer surgeon, who studied human and animal physiology, and a dedicated doctor who knew how to apply his knowledge and expertise for the benefit of every one of his patients.

In his obituary, William Lower $\mathrm{E}^{17}$ referred to Crile's human and scientific characteristics, especially his enthusiasm for understanding life and death and ends his description with the following paragraph: some men are given to make a living, or to make a more refined heritage. George Washington Crile gave us more than anociassociation; we inherited his enthusiasm for finding the answers to the facts we observe every day in our medical profession.

\section{Funding details}

None.

\section{Acknowledgments}

None.

\section{Conflicts of interest}

Authors declare that there is no conflicts of interest.

\section{References}

1. Crile GW, Lower WE. Anoci-Association. In:Rowland AF (Ed.), WB Saunders Company, Philadelphia, USA, 1914. p.400.

2. Crile GW. The kinetic theory of shock and its prevention through anociassociation (Shockless operation). The Lancet. 1913;182(4688):7-16.

3. Crile G. In George Crile. An Autobiography. Volume I-II. JB Lippincott Company. Philadelphia. 1947.

4. Crile G. The thyroid gland. WB Saunders Company. 1922.

5. Hannan SA. The magnificent seven:a history of modern thyroid surgery. Int J Surg. 2006;4(3):187-191

6. Woolf CJ. Evidence for a central component of post-injury pain hypersensitivity. Nature. 1983;306(5944):686-688.

7. Woolf CJ, Chong MS. Preemptive analgesia-treating postoperative pain by preventing the establishment of central sensitization. Anesth Analg. 1993;77(2):362-379.

8. WallPD. The prevention of postoperativepain.Pain. 1988;33(3):289-290.

9. Dickenson AH, Sullivan AF. Subcutaneous formalin-induced activity of dorsal horn neurones in the rat:differential response to an intrathecal opiate administered pre or post formalin. Pain. 1987;30(3):349-60.

10. Katz J. George Washington Crile, anoci-association, and pre-emptive analgesia. Pain. 1993;53(3):243-245.

11. Tverskoy M, Cozacov C, Ayache $M$, et al. Postoperative pain after inguinal herniorraphy with different types of anesthesia. Anesth Analg. 1990;70(1):29-35.

12. Crile GW. The present status of anociation:A critical review. Ann Surg. 1927;86(2):251-244.

13. Crile GW. The resuscitation of the apparently dead and a demonstration of the pneumatic BP device. Trans South Surg and Gynaecol Ass. 1904; 16:361-370.

14. LateefF, Kelvin T. Military anti-shock garment:Historical relic or a device with unrealized potential? J Emerg Trauma Shock. 2008;1(2):63-69.

15. Hedley-Whyte J, Milamed DR. Blood and war. Ulster Med J. 2010;79(3):125-134.

16. Loop FD. Dr. George W. Crile. The father of physiologic Surgery. Clev Clin J Med. 1993;60(1):75-80.

17. Lower WE. George Surgery. 1944;119(4):612-615
Crile:1864-1943. Ann of 